\title{
Regime estético e campo literário: uma leitura de Jacques Rancière
}

\author{
Lucas Bandeira de Melo Carvalho ${ }^{a}$
}

\begin{abstract}
Resumo
Neste trabalho, pretendo pensar a importância do trabalho de Jacques Rancière para a discussão de literatura e política e os limites de sua teoria. Para isso, além de rever seus conceitos e críticas recentes a seus livros, uso o ponto de vista brasileiro como prisma privilegiado para avaliação de sua obra. Sugiro caminhos para discutir como a literatura contemporânea pode ser lida à luz de conceitos como "partilha do sensível" e "regime estético" e apontar os riscos de domesticar essa produção ao recorrer a uma teoria que pensa a partir de objetos europeus e canônicos.
\end{abstract}

Palavras-chave: Política; Jacques Rancière; Literatura brasileira. 
O debate atual sobre literatura e política deve muito a Jacques Rancière, que, principalmente desde 1989, com A noite dos proletários, vem fazendo uma importante revisão de uma série de conceitos estéticos e políticos. Mas foi a partir de 2005, quando saiu no Brasil A partilha do sensível, que seus termos se tornaram correntes na discussão estética no país. E não sem razão, já que nos ajudam muito a sair das aporias tanto das teorias formalistas quanto das sociológicas. Apesar disso, é necessário apontar os limites de uma aplicação direta de sua teoria na literatura brasileira. Minha proposta aqui é explicar alguns dos conceitos de Rancière, apontar teorias com as quais se relacionam as críticas contemporâneas a seu modelo e, por fim, sugerir uma posição teórica em relação a eles.

A teoria de Rancière começa a ser elaborada como reação ao marxismo de Louis Althusser, de quem foi aluno. Rancière participou com Althusser e Étienne Balibar de Ler o Capital (1965), mas rompe com o professor depois de maio de 68. Para Rancière, a crítica do antigo mestre ao movimento mostrava a dificuldade do marxismo francês da época de ligar teoria e prática. Ele encontra no autor de A favor de Marx os vícios da relação do intelectual com a história e a política: a crença de que haveria uma explicação para o devir histórico - o "desejo de tornar a história razoável" (id., p. 224) - e a ideia de que o intelectual deveria dirigir-se a alguém - a imagem do proletário cuja consciência de classe precisaria ser despertada. E esses dois enganos apareceriam de maneira clara na metáfora de que o mundo seria uma obra - um texto - que teria respostas esperando por nós; que deveríamos formular as perguntas corretas, e que seríamos impedidos de formulá-las pela ideologia, conceito central em Althusser.

É contra isso que Rancière vai se bater. Para ele, a verdadeira emancipação não depende da sublevação de uma classe contra os aparelhos do Estado, inclusive aqueles cuja função seria ideológica, mas de uma subversão da própria ideia de classe. E essa subversão tem dois nomes, indissociáveis um do outro: política e estética. Dessa maneira, ele pretende resolver uma aporia - que hoje soa datada - da teoria marxista: como uma prática, artística, política ou cotidiana, pode ser transformadora se está sempre sujeita à estrutura de classe? A resposta seria: mostrando como essa estrutura é baseada 
em hierarquias ilusórias de capacidades, e não fazendo o espectador acordar para essa hierarquia.

Como comentou Rancière em uma entrevista: "Passei a interpretar a teoria de Althusser como aquela na qual a ação política dependerá sempre da ciência transmitida por pessoas com a autoridade para fazê-lo" (RANCIÈRE, 2014b). Ele então vai desenvolver a ideia de que os grandes reformadores sociais (como Marx e Rousseau), por mais bem-intencionados que fossem, reforçavam as hierarquias que pretendiam abolir, já que mantinham as duas posições: o mestre e o discípulo, o guia e o guiado. E os paradoxos dos reformadores sociais são os mesmos da arte política: sua eficácia depende de negar a igualdade daqueles que reformadores e artistas pretendem defender.

Para rebater esse ponto de vista, que chama de pedagógico, Rancière precisa realizar o duplo movimento de, primeiro, combater a ideia de que as principais hierarquias têm base econômica e, segundo, combater a ideia de que as transformações políticas precisam de uma ciência ou uma consciência de classe. De maneira muito diferente, a principal transformação seria a da "divisão das ocupações, a qual se inscreve, por sua vez, em uma configuração do sensível" (RANCIËRE, 2017a, p. 8).

A partir desse projeto, a teoria de Rancière relaciona uma série de conceitos-chave - regimes das artes, eficácia artística, partilha do sensível, dissenso, democracia, política e polícia da arte, hierarquia e igualdade de inteligências - e um personagem: o "qualquer um". Seja para analisar a história da arte - em A partilha do sensivel -, a democracia representativa em $O$ ódio à democracia - ou a relação entre arte e público - em alguns ensaios de $O$ espectador emancipado -, esses conceitos formam uma rede conceitual coerente e rigorosa.

Essa rede conceitual busca relacionar dois termos que nem sempre andaram em harmonia: política e estética. Rancière quer mostrar como eles sempre foram indissociáveis. Não faria sentido falar de estetização da política porque, desde o princípio, política significou

“a partilha do sensível do que dá forma à comunidade [...] uma relação entre os modos do fazer, os modos do ser e os do dizer; entre distribuição dos corpos, de acordo com atribuições e finalidades, e a circulação do sentido; entre a 
ordem do visível e a do dizível [...], entre o que pertence à ordem do discurso e o que depende do simples ruído dos corpos" (id., p. 7-8).

A questão, portanto, é a redivisão da ordem do discurso - a partilha do sensível.

Para Rancière, houve ao menos três regimes do sensível na história ocidental.Vejamos como ele os define em A partilha do sensivel. "No que se diz respeito ao que chamamos arte", escreve,

"pode-se com efeito distinguir, na tradição ocidental, três grandes regimes de identificação. Em primeiro lugar, há o que proponho chamar um regime ético das imagens [...] Há um tipo de seres, as imagens, que é objeto de uma dupla questão: quanto à sua origem e, por conseguinte, ao seu teor de verdade; e quanto ao seu destino: os usos que têm e os efeitos que induzem" (RANCIÈRE, 2009, p. 28).

Isto é, no primeiro regime (cujo patrono parece ser Platão), o que torna a imagem legítima ou ilegítima é seu valor pedagógico (seu destino) ou sua origem nobre. Valores e origens muitas vezes religiosos. A arte deve se adequar ao etos da sociedade e, portanto, não se individualizar.

No segundo regime, poético ou representativo (mimético), as artes se individualizam, mas de maneira hierarquizada:

“O princípio mimético, no fundo, não é um princípio normativo que diz que a arte deve fazer cópias parecidas com seus modelos. É, antes, um princípio pragmático que isola, no domínio geral das artes (das maneiras de fazer), certas artes particulares que executam certas coisas específicas, a saber, imitações" (id., p. 30).

Isto é, nesse regime - que podemos considerar aristotélico -, as artes não estão sujeitas a um princípio único organizador da sociedade, mas todas elas dependem de uma classificação do que pode ser representado, com que materiais, por quem e para quem.

A esses dois regimes da arte, por fim, contrapõe-se um terceiro - o regime estético. "O regime estético das artes", escreve,

"é aquele que propriamente identifica a arte no singular e desobriga essa arte de toda e qualquer regra específica, de toda hierarquia de temas, gêneros e artes [...] o regime estético das artes é o verdadeiro nome daquilo designado pela denominação confusa de modernidade" (id., p. 33-4, grifo meu). 
É o momento em que há, na literatura,

“a subversão das hierarquias da representação (o primado narrativo sobre o descritivo ou a hierarquia dos temas) e a adoção de um modo de focalização fragmentada, ou próxima, que impõe a presença bruta em detrimento dos encadeamentos racionais da história".

Ao mesmo tempo, esse regime estético corresponde a um momento em que cada arte afirmaria "a pura potência da arte explorando os poderes próprios do seu médium específico" (ibid., p. 38). Cada linguagem, portanto, tem apenas sua própria potência para justificar a si própria, uma vez que a hierarquia entre linguagens se desfaz. Esse caminho, no entanto, leva cada arte cada vez mais para perto da matéria básica de que é feita.

Não creio necessário me estender no que seria o regime estético, mas o importante é notar que essa ruptura democrática (antiplatônica, antiaristotélica) significa uma autonomização da arte que independe da criação de campos específicos autônomos. Não é uma autonomia ligada à criação de grupos capazes de legitimar suas produções por meio de critérios próprios, como na sociologia de Pierre Bourdieu, mas ligada a uma alteração de paradigmas sensíveis, isto é, da forma como vemos, produzimos e fazemos circular produções sensíveis.

Isso não significa que os regimes anteriores tenham sumido. Eles continuam naquilo que Rancière chama de polícia da estética. A estética policial tenta recompor as hierarquias de gêneros, temas e sujeitos; a política da estética, por outro lado, é formada pelos movimentos de dissenso, democráticos, que rompem as hierarquias. Tanto a política quanto a polícia estão ligadas a formas diferentes de eficácia, que correspondem aos diferentes regimes da arte. De certa forma, parece que as formas de eficácia são resíduos dos regimes defuntos que não foram extirpados da sensibilidade contemporânea.

O primeiro modelo de eficácia, explica Rancière em "Paradoxos da arte política", seria o da tradição mimética, o modelo próprio ao regime representativo das artes. Essa eficácia supõe que a intenção e o resultado da arte política mantêm uma relação de causa e efeito, "a não ser que se suponha o artista inábil ou o destinatário incorrigível" (RANCIÈRE, 2012, p. 52). Há, portanto, uma "continuidade entre as formas sensíveis da produção artística e as formas sensíveis segundo as quais são 
afetados os sentimentos e os pensamentos de quem as recebe" (id., p. 53), uma relação direta, imediata, invariável, entre a intenção do artista e o efeito. Para que funcione, essa lógica depende de tudo ser previamente classificado: quais temas serão tratados por que tipo de artistas, distribuídos por quais meios, para quais públicos, com qual linguagem.

Na Europa do século XVIII, esse modelo foi contestado de duas maneiras. Uma delas era o ataque frontal, que Rancière encontra em Rousseau: "a ruptura da linha reta suposta pelo modelo representativo entre a performance dos corpos teatrais, seu sentido e seu efeito" (id., p. 54), substituída por uma arte sem representação, "que não separa a cena da performance artística e a da vida coletiva" (id., p. 55). Essa arte que pretende abolir a si mesma inauguraria uma nova eficácia, mas ainda pedagógica: a da "imediatez ética" (id., p. 56). Ou seja, desejase denunciar a ilusão da causalidade direta das intenções do artista, que operava no modelo mimético-representativo, mas ela é substituída por outra pedagogia, que ainda pressupõe que o espectador possa ser guiado pelo autor.

A segunda forma de ruptura, que inaugura uma terceira forma de eficácia, é a eficácia estética, própria do regime estético da arte. Esse novo modelo deve sua eficácia à própria separação, à "descontinuidade entre as formas sensíveis da produção artística e as formas sensíveis através das quais os espectadores, os leitores ou os ouvintes se apropriam desta" (id., p. 56). A grande revolução do sensível seria essa suspensão de qualquer relação lógica, determinável e determinista, entre a intenção do artista, de um lado, e o efeito no espectador ou na comunidade, de outro. Ou seja, a eficácia estética é a eficácia da liberdade que existe em uma experiência do sensível que não é mais marcada por certas hierarquias, como quem determina o sentido e a linguagem da obra e quem determina quem pode falar sobre o que, e quem pode receber qual arte.

É a eficácia do dissenso - a liberdade do sentido plural da obra, determinado por cada receptor independente da intenção autoral -, da política, da arte que "não se dirige a nenhum público específico, mas ao público anônimo indeterminado dos visitantes de museus e leitores de romances" (id., p. 58). E o modelo dessa liberdade é a escrita: "a democracia é o regime da escrita", escreve ele no prefácio de Políticas da escrita (RANCIÈRE, 2017a, p. 10), e continua: "é o regime errante da 
letra órfã cuja legitimidade nenhum pai garante". E conclui que "há democracia - e política, consequentemente - porque há palavras sobrando, palavras sem referentes e enunciados sem pais, que desfazem qualquer lei de correspondência entre a ordem das palavras e a das coisas" (id., p. 18). A eficácia estética, cujo modelo é, portanto, a literatura escrita, realiza o trabalho de romper as ideias de classe e outras hierarquias, como a hierarquia de inteligências. Podendo produzir o que bem entendem e receber o que e como bem entendem, os indivíduos configuram as hierarquias sociais, revolução verdadeira que precederia as revoluções sociais.

Essa definição tem duas características importantes. Por um lado, como ela trabalha no nível paradigmático, é útil para pensar o que significa política da arte. No entanto, por outro, ela ignora os aparelhos que operam na sociedade e, mais do que isso, como operam em cada sociedade específica. Que sentido faz falar fora da França em "público anônimo indeterminado dos visitantes de museus e leitores de romances"?

Antes de desenvolver essa crítica, devemos, porém, tentar amarrar melhor o que é essa eficácia estética e sua homologia com a democracia. Política e estética se relacionam de três maneiras. Primeiro, há uma estética da política, isto é, a política, como forma de conflito, de dissenso, reconfigura o que é visível. Isso porque a política não é uma simples luta pelo poder, mas uma luta pelo que é possível ver, dizer, fazer. Uma segunda relação é a arte política - ou a política dos artistas -, que é o uso da arte como uma forma de persuasão política, de esclarecimento do público - de maneira semelhante aos cientistas sociais -, ou, pelo contrário, uma tentativa de narcotizar o público. A terceira relação, que precede a política dos artistas - e muitas vezes a contradiz, isto é, contradiz a intenção - é a política da estética,

"as novas formas de circulação da palavra, de exposição do visível e de produção dos afetos [que] determinam capacidades novas, em ruptura com antigas configurações do possível" (RANCIÈRE, 2012, p. 63).

Não é, portanto, a intenção do artista ou a boa fatura da obra que reconfiguram os possíveis - e democracia significa expansão dos possíveis -, mas a maneira como a arte rompe as hierarquias, as barreiras, as falsas sobredeterminações (o artista como superior ao espectador, o intelectual como superior 
ao proletário, etc.). Portanto, estética e política se relacionam porque a política sempre é estética (a estética da política) e porque a arte sempre tem como efeito uma reconfiguração do sensível (a política da estética), mesmo quando sujeita à política dos artistas.

Podemos concluir que estética, política e democracia operam analogamente como forças de dissenso dentro da sociedade, fraturando a hegemonia do regime representativo, policial e oligárquico. São formas de dissenso que, reforço, quebram as hierarquias de quem tem acesso às imagens e às palavras, do que pode circular, de quais formas podem tratar do quê. E há certo primado do sensível sobre outras esferas: a transformação do sensível precede tanto as revoluções teóricas - tema de $O$ inconsciente estético - quanto as revoluções políticas. Sua eficácia não depende da dinâmica entre estrutura e superestrutura, mas sim da anulação das divisões em que essa dinâmica se baseia, como as divisões de classes e gênero. $\mathrm{Ou}$, como ele escreve em $\mathrm{O}$ fio perdido ao falar de Madame Bovary, essa eficácia significa a "afirmação da capacidade dos anônimos", rompendo "essa atribuição identitária" (RANCIÈRE, 2017b, p. 32-3).

Há, no entanto, outro elemento essencial para a eficácia estética: a mediação (mas não a mediação da práxis política). A obra é eficaz, escreve Rancière no ensaio "O espectador emancipado", porque é uma "terceira coisa de que nenhum deles é proprietário" (RANCIÈRE, 2012, p. 19), nem o autor nem o leitor, nem o ator nem o espectador, nem o mestre nem o aprendiz. Por isso o erro das pedagogias que querem romper a distância entre os polos: a liberdade de cada lado depende dessa distância - que podemos etimologicamente chamar de crítica, de kritikē, "separar", "discernir". É essa distância o elemento material que medeia duas liberdades e duas inteligências iguais em diferença. Caem no erro de tentar abolir a mediação tanto as pedagogias que acreditam ser possível passar sem mediação da intenção para o efeito quanto aquelas que creem que sua missão é abolir a mediação. Pretender abolir a mediação é "antecipar o efeito" (id., p. 25) e com isso eliminar a liberdade do espectador, recolocar a autoridade no produtor, que teria resposta para qualquer tentativa de interpretação. Apenas a distância estética permite que o autor seja traído e que a igualdade se estabeleça. 
O edifício teórico que Rancière constrói é incontornável para pensar a política da estética hoje. Com ele, podemos debater a complexidade da relação entre a obra e o mundo e como o efeito de uma obra de arte sempre será estético e nunca poderá ser antecipado por uma pedagogia que preceda a experiência. No entanto, se a mediação sai fortalecida, as instâncias de legitimação e de controle são apagadas de uma maneira um pouco mágica, como se ignorá-las fosse aboli-las. Isso é possível porque, em vez de partir do dado sociológico, Rancière analisa - por meio de uma reconstituição um pouco problemática da história da arte - uma mudança de paradigma. Como já vimos, no regime representativo absolutista, havia instituições fortes que determinavam o que era dito e visto, como e por quem; no regime estético, qualquer um pode falar ou ver qualquer coisa e interpretar à sua maneira, e essa interpretação do subalterno - ou melhor, a multiplicação de interpretações de maneira não hierárquica - é exatamente o dissenso, cuja força - mais do que a militância e qualquer forma de organização coletiva liderada por algum tipo de mestre - vai produzir a transformação efetiva.

Percebemos agora quais conceitos Rancière combate ou tenta substituir. Primeiro, claro, o de ideologia, principalmente em sua versão althusseriana, que a aproxima do inconsciente freudiano - isto é, de que a compreensão do mundo de cada sujeito depende da classe a que ele pertence e que essa dependência não é clara para o próprio indivíduo. Ele também combate a ideia de um primado da economia, ou das relações de produção, substituído pelo primado do sensível e da experiência individual. E, por fim, combate as teses de Pierre Bourdieu de que, na nossa sociedade, consumir cultura é uma forma de distinção - e, por isso, de poder - e de que há instâncias de legitimação (os campos e suas estruturas estruturantes) do que pode ser visto e falado e como. No entanto, enquanto Rancière trabalha com modelos conflitantes que se mantêm há séculos, Bourdieu discute estruturas de poder operantes num momento e num ambiente específicos, e a teoria parte das necessidades desse objeto concreto. Ao igualar esses níveis de abstração, talvez Rancière cometa um equívoco que ele próprio atribui, em $O$ ódio à democracia, aos críticos da democracia: "situar todo fenômeno no mesmo plano, atribuindo a todos a uma única e mesma causa" (RANCIÈRE, 
2014a, p. 41). Além do nível de abstração - ou dos planos -, há uma diferença histórica. Afinal, as ideias teóricas não surgem do nada, mas dependem dos possíveis do campo teórico em cada momento histórico. Marx pensava a ideologia e o primado da economia de dentro da Revolução Industrial, quando a jornada de trabalho havia se tornado independente dos ciclos da natureza - trabalhar enquanto havia sol - e chegava a níveis desumanos. Rancière fala de outro lugar, do centro da democracia liberal do final do século $X X$, em que a penúria foi virtualmente abolida - ao menos na França -, e não é à toa que seu objeto continua restrito à arte europeia ou americana, e não se estende à cultura de países ainda assolados pela miséria.

É essa diferença entre o foco em paradigmas abstratos e o foco nas práticas pontuais que leva Rancière a escrever a frase que já citamos aqui: "A estátua [...] já não se dirige a nenhum público específico, mas ao público anônimo indeterminado dos visitantes de museu e dos leitores de romance" (RANCIÈRE, 2012, p. 58). Essa imagem utópica, que identifica espaços em que o acesso e a interpretação divergente são permitidos, só é possível em lugares onde essas barreiras não são mais tão claras (para não falar das barreiras de gênero que mesmo na sociedade francesa continuam operando). Dessa maneira, a teoria dos paradigmas acaba ignorando parte da mediação, que ela pretende manter. Apaga-se toda a complexa hierarquia social que Bourdieu tenta destrinchar. Afinal, somos capazes de identificar todas as hierarquias que agem em nossa sensibilidade, ou estamos sujeitos a enxergar democracia onde só há democracia para quem está em certo lugar (de fala, de visão, de interpretação)? A teoria dos regimes estéticos limitase ao exemplo ideal: "O princípio [da eficácia estética é] a suspensão de qualquer relação determinável entre a intenção do artista, a forma sensível apresentada num lugar de arte, o olhar de um espectador e um estado da comunidade" (ibid., grifo meu). O problema é que, de olho na utopia, fica-se entregue a um livre mercado de "modos de ver". A única forma de luta legítima - já que a eficácia pedagógica apenas confirmaria a polícia da estética - é o dissenso, o trabalho do excesso.

Duas críticas recentes seguem essa direção ao apontar os limites do modelo de Rancière. Comentando Aisthesis, em que Rancière aplica a ideia de regime estético a casos específicos, "cenas", o crítico de arte Hal Foster (2013) identifica 
três problemas. O primeiro, que não nos interessa aqui, seria a falta de originalidade. A segunda crítica de Foster é à utilidade operacional da ideia de regime. Segundo o crítico, Rancière mantém de Althusser o projeto de "evitar o grande arco da história" e, por isso, sua fascinação com as ordens epistêmicas (que ele vai chamar de "racionalidades" ou de "regimes"). Para Foster, assim como acontece com o conceito de discurso em Foucault, é difícil entender como essas categorias são determinadas. O regime, como o discurso, "torna-se não apenas sua própria causa como também agente por conta própria" (ibid.), agência pulverizada igualmente entre todos os indivíduos. Como o discurso, o regime não tem exterior, ele inclui suas próprias causas - e sua própria contestação (a resistência, o dissenso). Por isso, essas categorias não captariam bem a mudança histórica. A inespecificidade delas - quer dizer, é ontologicamente impossível identificar de onde vem ou como ocorre a mudança - faz com que o conceito "explique ao mesmo tempo muito e pouco" e os "insights sejam frequentemente tão gerais que parecem ao mesmo tempo grandiosos e óbvios" (ibid.).

O resultado disso - a terceira e mais pesada crítica de Foster - é que a política da arte de Rancière beiraria "o pensamento mágico", ainda mais quando se considera que hoje a arte não tem a agência que o filósofo francês lhe atribui. A consequência dessa valorização de uma "redistribuição do sensível por meio da arte contemporânea" - uma miragem quando comparada com o poder do capitalismo de "transformar coisas em símbolos" - é que essa política vira um "ópio da esquerda do mundo da arte" (ibid.): os artistas e os críticos apegam-se à possibilidade de eficácia estética e ignoram os movimentos históricos concretos, enquanto fazem parte de um mercado pujante, alimentado pelo grande capital.

Foster abre caminho para um questionamento duplo. Por um lado, Rancière revoga o direito da crítica - tanto da arte crítica quanto do pensamento crítico. $\mathrm{O}$ autor de $\mathrm{O}$ retorno do real resume assim a tese de Rancière: "Primeiro, não apenas a consciência não é transformativa per se, mas 'o explorado raramente precisa de uma explicação das leis da exploração'". Continua ele: 
Segundo, a arte crítica depende de sua própria produção de uma audiência passiva que então a arte presume tornar ativa. Terceiro, a arte crítica "pede aos espectadores para descobrir os signos do capital por trás dos objetos e comportamentos cotidianos", mas ao fazer isso apenas confirma a "transformação das coisas em signos" que de qualquer maneira o capitalismo desempenha. Por fim, a arte crítica está presa no círculo vicioso de sua própria produção. (ibid.)

Ou seja, para Rancière a arte crítica é perversa porque, por um lado, propõe uma hierarquia - os conscientes versus os alienados - e, por outro, reifica as relações - Rancière diria: produz a diferença entre o polo ativo e o passivo, o produtor e o destinatário - e naturaliza a exploração (transformada em espetáculo), "a lógica policial da equivalência do poder do mercado e do poder da denúncia" (apud FOSTER, op. cit.).

O que Rancière critica, porém, talvez seja um estereótipo da crítica do estereótipo. Ele escolhe um tipo de crítica que atacaria paternalisticamente e neutralizaria a verdadeira crítica, que é, para ele, a distribuição do sensível pela multiplicidade de anônimos: "Crítica é a arte que desloca as linhas de separação" (RANCIÈRE, 2012, p. 75). Mas para isso ele precisa criar um inimigo ideal a ser refutado. Por exemplo: no ensaio em que trata de A câmara clara, "A imagem pensativa" (id., p. 103-25), ele necessita produzir uma versão do livro de Barthes que se encaixe em sua ideia de regimes da arte. Assim, para refutar a distinção entre punctum e studium, ele interpreta o livro como uma investigação do estatuto da imagem, quando na verdade A câmara clara é, como insiste Didi-Huberman, "o livro da consciência rasgada do semiólogo", no qual "a noção de punctum parece perder em pertinência semiológica o que ela ganha em pertinência fenomenológica"; fala de algo "exprimível não em termos de estrutura, mas de existência" (DIDI-HUBERMAN, 2013b, p. 338-9). Ou seja, Rancière trata como um conceito estrutural algo que é fenomenológico (isto é, Barthes fala de como nossa visão é absorvida "diante da imagem", não de como a imagem funciona estruturalmente). Do mesmo modo, Rancière precisa criar uma visão utópica da "revolução estética". É essa visão utópica que ele desenha quando trata de John Keats em O fio perdido: a era revolucionária, que produziu escritores como Keats, diz ele, 
traz, na verdade, duas lições exatamente contraditórias: uma é que o primeiro plebeu que aparece pode, graças a sua inteligência e a sua vontade, se tornar o mestre da Europa; a outra é que se o primeiro plebeu que aparecer renunciar à pretensão de impor isso aos outros através de sua vontade, poderá entrar em um diálogo com os deuses e seus poetas. (RANCIÈRE, 2017b, p. 84)

O segundo questionamento é metodológico. Qual é o método de Rancière para sua crítica da crítica? O que ele faz senão denunciar a ilusão daqueles que denunciam as ilusões do homem comum; senão denunciar a ideologia (os interesses ocultos e inconscientes da classe intelectual) por trás da crítica da ideologia? Ou seja, Rancière usa o conceito de ideologia sem nomeá-lo. Qual é essa ideologia? Para ele, Marx, Althusser e Barthes não perceberiam que não há nada para ler sob o signo, que o homem comum não é alienado, porque era a suposição da alienação que justificava suas obras. $\mathrm{O}$ trabalho de procurar causas (Marx) e significados (Barthes) escondidos apenas manifestaria o teor antidemocrático do pensamento idealista herdeiro do platonismo e o desejo de manter os privilégios dos intelectuais, "mestres" do povo.

O problema seria, como vimos, que esses pensadores trabalham ainda dentro da racionalidade platônica que acredita que a verdade está escondida por um mundo das aparências que deve ser denunciado ou, pelo contrário, da racionalidade aristotélica que acredita que o todo é uma unidade orgânica em que cada parte tem sua função - enquanto na verdade o todo é "uma rede sem fim de fibra e de sinapses que não se deixa aprisionar em uma unidade de um organismo ou mobilizar na unidade de uma ação" (RANCIĖRE, 2017b, p. 130). Ele, então, opõe a verdade "reticular" da racionalidade estética à prisão representativa e clássica em que esses pensadores ainda estariam. O problema é que ele recorre ao mesmo tom para revogar a legitimidade do discurso teórico. Isto é, o método de Rancière é emprestado do objeto de sua crítica.

Por outro lado, Rancière trabalha os mesmos objetos dos autores que critica, e muitas vezes o conteúdo de suas análises não se afasta tanto das interpretações anteriores. A ideia de que o realismo francês não era uma questão de mimese, mas uma relação do escritor com o tema, já havia sido sugerida por Barthes e desenvolvida longamente por Bourdieu. 
${ }^{1} \mathrm{O}$ termo é tirado de Fried, que o elabora em Absorption and Theatricality: Painting and Beholder in the Age of Diderot. O termo absorption (absorção) significa a "ficção da inexistência do espectador", que Fried encontra nas artes plásticas da metade do século XVIII, principalmente em sua recepção por Diderot (que não usa o conceito). Fried adota dois adjetivos, absorptive, que usa em expressões como "absorptive states", "absorptive activities", e absorbed, como em "figures absorbed"; isto é, estados ou atividades absorventes - o que causa a absorção - e personagens absortos - o tema absorto em si mesmo. Em francês, a tradução costuma ser "absorbement" ou "absorption" (subs.), "absorbant" e "absorbé" (adj.).
Quando chega ao presente, porém, o que Rancière tem a dizer? Vemos, por exemplo, como em O ódio pela democracia aparecem referências a reality shows. As cinco vezes servem apenas para caracterizar a figura que hoje desperta ódio dos inimigos da democracia, como Alain Finkielkraut: "o retrato falado do homem democrático: jovem consumidor imbecil de pipoca, reality shows, safe sex, previdência social, direito a diferenças e ilusões anticapitalistas ou altermundialistas" (RANCIÈRE, 2014a, p. 112-3). São referências que apenas caracterizam pela via negativa o homem antidemocrático, enquanto a análise da eficácia estética permanece confinada à arte autônoma cujo modo de produção Rancière não reconhece existir.

Apesar dessas ressalvas que podemos fazer à teoria de Rancière, ela tem o mérito, que Foster não considera, de transformar o encontro entre estética e política, formas de vida e formas de figuração artística, em um sistema sem restos, que dá conta das contradições do processo histórico e de certa forma redime o presente. Ele nos dá instrumentos para entender a porosidade entre arte e política.

Outro crítico da teoria de Rancière é Walter Benn Michaels. Ele é autor de um importante estudo sobre o naturalismo americano e sua relação com o capitalismo da virada do século XIX para o XX (The Gold Standard and the Logic of Naturalism, 1987) e coautor, com Steven Knapp, de "Against Theory" (1982), em que combatiam a teoria literária, representada por Paul de Man e Stanley Fish, entre outros.

Em 2011, Michaels escreveu um ensaio interessante sobre a "estética neoliberal". O texto tem uma estrutura curiosa, desenvolvendo temas que parecem não se conectar. Começa com Diderot e a questão da contemplação (behold): as pinturas são feitas para ser contempladas, por isso devem ser valorizadas aquelas que trazem figuras "absortas" (absorbed $)^{1}$ em suas próprias atividades, "inconscientes de que estão sendo observadas", "removidas do mundo fora da pintura". A discussão de Diderot leva o debate para Michael Fried, autor de outro ensaio fundamental, "Arte e objetidade". Para Fried, o oposto da obra que basta a si mesma - que é aquela que merece propriamente ser chamada de arte - é a obra "teatral", que encena sua enunciação. E defende uma arte pura contra aquela que depende do espectador. Os polos com que o autor de Absorption and Theatricality trabalha são, de um lado, a arte 
2 "O observador baudelairiano não corre, como o de Poe, atrás dos personagens que atraíram sua atenção, nem mesmo daquela passante que ele teria amado" (RANCIÈRE, 2017b, p. 115). que funciona segundo os princípios de unidade, absorção e foco no objeto (a objetidade); de outro, aquela que funciona segundo os princípios de teatralidade, efeito, foco no espectador (que deve ser capaz de interpretar a intenção do autor). Ou seja, uma obra que basta a si mesma, outra que existe apenas se o espectador consegue identificar a intenção do artista.

A discussão da tese da dicotomia entre arte absorvente e arte teatral serve para Michaels introduzir a crítica a Rancière. Ele comenta uma pintura de Batolormé Estevan Murillo, Meninos comendo uvas e melão (1645-46), que tanto Rancière quanto Fried analisam. Para este, ela seria um exemplo da obra absorvente, cujo tema está contido em si mesmo: meninos absortos em uma atividade. Pouco importa o que eles fazem, mas apenas o fato de estarem ali, absorvidos apenas em si mesmos. Rancière, por sua vez, busca uma explicação diferente em Hegel, para quem o que impressiona na obra é seu total desprezo pelo exterior (o que Fried chamaria de absorção), mas esse desprezo não separa a pintura do mundo. Rancière sugere que, em vez de absortos em sua tarefa, eles estão "fazendo nada e preocupando-se com nada" (apud MICHAELS, op. cit.). É esse não fazer nada que salva os garotos não apenas da passividade, mas os insere em um tipo de arte que é arte "em termos de não instrumentalidade" (id.). É um tema que encontramos em diversos momentos da obra de Rancière. Por exemplo, ele elabora essa valorização do não fazer, da contemplação contra a ação, em seu ensaio sobre Keats e Baudelaire: a defesa do devaneio, do poeta que, em vez de ir atrás do passante na rua, como Poe, apenas o observa da janela, como Baudelaire ${ }^{2}$.

Estamos de novo tratando da partilha do sensível e da eficácia estética, que agora deve quebrar até mesmo a hierarquia entre ação e pensamento. A nova eficácia depende de reconhecer que não sabemos em que ponto pensamento se torna ação e muito menos "o momento em que a causa começa a agir"; tampouco é possível determinar "o ponto onde seu efeito termina" (RANCIÈRE, 2017b, p. 130). Ou seja, o que torna o pensamento do observador baudelairiano eficaz não é a maneira como ele compreende o fluxo da cidade capitalista, mas a simples entrega ao devaneio, que transforma a partilha daquilo que é possível ver e fazer. 
Mas precisamos voltar à pintura de Murillo. Assim como as fotografias de Walker Evans em Let Us Now Praise Famous Men (1941), de James Agee - reportagem clássica que os dois fizeram para a Fortune sobre os efeitos da grande depressão dos anos 1930 na vida dos meeiros americanos -, ela ilustraria a transformação operada pela arte: a inclusão da não arte permite que os sujeitos representados no quadro barroco ou fotografados "se apropriem das capacidades estéticas que os retiram de uma identificação social", que exerçam sua liberdade de uma maneira que "sua condição social supostamente proíbe" (apud MICHAELS, op. cit.). O problema dessa leitura, observa Michaels, é que a neutralização da hierarquia estética funciona, para o teórico francês, como neutralização da hierarquia social. Não se trata de criar uma igualdade, mas de reconhecer uma igualdade que já existe. A desigualdade seria produto de uma ilusão social, que nos faz crer que há diferenças de inteligências (o que Rancière elabora em $O$ mestre ignorante), e a crítica social, seja ela a da sociologia de Pierre Bourdieu ou do reformismo marxista, reforçaria em vez de questionar as hierarquias que sustentam essa ilusão. A mudança deve começar pela compreensão de que essas hierarquias são uma ilusão social.

Mas nem toda desigualdade depende de uma ilusão social, e muitas ilusões sociais são reforçadas por desigualdades não ilusórias. Há aquelas que são produzidas "por uma economia, não por um modo de ver [not a vision]". Ignorar a existência da injustiça criada por fatores econômicos equivaleria a "um compromisso com a igualdade que pode coexistir alegremente com a desigualdade econômica" (MICHAELS, id.). A diferença crucial, continua Michaels, está entre duas maneiras de encarar o efeito das hierarquias sensíveis. Uma coisa seria considerar que "os meninos mendigos e os camponeses [são] prejudicados por nossa falsa visão hierárquica deles" e outra considerá-los "prejudicados pelas condições que nossa visão pode sancionar ou criticar, mas não produzir" (id.) - ou seja, as hierarquias sensíveis podem apenas reforçar uma divisão cuja gênese é, para Michaels, histórica e econômica. E continua:

“O dano característico que um meeiro negro sofre [por ele ser negro] ocorre em função da 'ilusão' do racismo; o que resta, o dano comum a fazendeiros negros e brancos, ocorre em função do capitalismo. Nenhuma ilusão é necessária" (id.). 
E realmente há, em Rancière, um primado do sensível sobre o econômico e o político. Quando fala do século XIX na França, ele escreve:

"Proibida a democracia na vida pública, [as elites] a viam triunfar nos tecidos baratos, nas carruagens, na canoagem, na pintura ao ar livre, nos novos modos das moças ou nos novos torneados dos escritores" (id., p. 118).

Antes, na Revolução Francesa, "a verdadeira revolução, a das instituições e dos costumes, já havia sido realizada nas profundezas da sociedade e nas engrenagens da máquina monárquica" (id., p. 25) antes da revolução política, social e econômica. A revolução sensível precede a política e econômica, assim como a revolução das hierarquias sensíveis precede a melhoria da vida dos trabalhadores. Apesar de identificar questões importantes, no entanto, Benn Michaels não está interessado em ver os limites da teoria de Rancière, mas em acusar a emergência de um pensamento sobre estética que valoriza a igualdade cultural e ignora a transformação econômica. Ele conclui o artigo denunciando a emergência "da crítica da discriminação (e, é claro, a celebração da diversidade) e do emprego dessa crítica como uma tecnologia para legitimar aquelas desigualdades que não são consequência do racismo e do sexismo" (id.), cuja consequência seria o surgimento de uma estética neoliberal, capaz de defender de maneira radical a igualdade dos temas enquanto convive harmoniosamente com as desigualdades sociais que estão na base dos meios de produção dessa mesma estética.

Há muito de esquemático na leitura e na posição de Michaels, que de certa forma retoma a antiga distinção de estrutura e superestrutura. Acredito ser possível identificar, como ele faz, uma homologia entre o neoliberalismo, que impõe a ausência de barreiras à circulação de capital - uma igualdade de acesso a "mercados eficientes", que muitas vezes significa transformar em mercadoria formas de visibilidade (comportamentos e identidades subalternos, ou a própria resistência ao neoliberalismo e às polícias da estética) -, e uma estética que coloca o peso na liberdade de propagação de discursos, em que a circulação, o fim das hierarquias, é a única coisa que conta, que é efetiva, ignorando que tipo de discurso 
é esse e negando a existência de classes sociais. Mas a leitura de Michaels tem ao menos dois problemas.

Primeiro, ele acredita ser possível uma separação entre a desigualdade econômica e a desigualdade de fundo identitário. No entanto, a desigualdade baseada em identidades (gênero, raça, crença, etc.), se tem base em uma ilusão social, por outro lado se incorporou ao funcionamento das instituições e aos hábitos individuais. A questão racial não pode ser separada da questão de classe, ainda mais em países como Brasil e Estados Unidos. Uma desigualdade é usada para manter e reforçar a outra desigualdade. Assim, Michaels de certa forma deslegitima as conquistas dos movimentos identitários. Em segundo lugar, ele ignora a contribuição de conceitos como partilha do sensível, dissenso e eficácia estética para uma discussão mais complexa das relações entre política e estética. Rancière nos ajuda a tentar resolver a antiga antinomia entre a arte (social) como reflexo e a arte (pura) como libertação das ilusões. Devemos apenas - e nisso Michaels e Foster contribuem - discernir os limites da teoria de Rancière e a necessidade de a lermos a partir de nossa posição e de nosso objeto.

O que proponho, portanto, é tentar reelaborar a crítica a partir do lugar de onde recebemos a obra de Rancière. Primeiro, como já apontamos, o problema de Rancière talvez esteja no momento de estabelecer os planos ou níveis de abstração. $\mathrm{O}$ engano não está na identificação de um nível em que a partilha do que se pode ver, falar e fazer pode ser revolucionária, mas em recusar um nível em que o dissenso estético não basta. E esses níveis, claro, se cruzam. Não podemos dizer que a diferença entre o relativo fracasso de Carolina Maria de Jesus (1914-1977) - que, depois do sucesso quando seu primeiro livro foi editado pelo jornalista Audálio Dantas, foi aos poucos expulsa do campo literário, principalmente quando quis afirmar sua obra como literária (ver MEIHY, 2016, e MEDEIROS DA SILVA, 2011) - e o relativo sucesso de autores contemporâneos como Ferréz se deva simplesmente a transformações do sensível. Também se deve a transformações do sensível, mas essa mudança, que ainda está em curso, precisou ser mediada por relações entre a esfera econômica e a esfera estética.

Outra maneira de colocar essa crítica é dizer que, por mais que Rancière pense numa eficácia que supere a distinção entre obra e mundo, a maior parte de seu objeto faz parte do campo 
estético hegemônico. E, por isso, parte da sujeição é excluída da equação. Embora os mendigos de Murillo possam significar uma mudança no regime de visibilidade, continuam objetos, não sujeitos do discurso artístico; assim como Agee e Evans eram os sujeitos da reportagem da Fortune que virou Let Us Now Praise Famous Men, o que leva Agee a escrever que tem "uma forte sensação de que o 'senso do belo', como praticamente tudo o mais, é um privilégio de classe" (apud MICHAELS, op. cit.). Ou seja, ao focar no objeto - embora comece seu percurso com a noite dos proletários -, Rancière deixa de lado a distância entre sujeito e objeto, que, embora deva ser sempre redefinida, existe. Ele chega a acenar com essa questão ao falar de uma "guerra civil" dentro da literatura, quando os escritores consagrados (como Victor Hugo) apadrinham de maneira ambígua os escritores proletários (como Constant Hilbey):

“Quando [escritores proletários] se apropriam da língua elevada do poema e dividem seu tempo em duas partes, uma do trabalho diurno da ferramenta com que ganham o pão e outra do labor noturno da caneta que dá a verdadeira vida, causam um transtorno à divisão do sensível em que também se apoiava o estatuto do poeta" (RANCIÈRE, 2017a, p. 18-9).

No entanto, continua ele, "esta guerra da escrita inscrevese mais profundamente na própria fábula literária" do que na disputa dentro do campo entre escritores de classes diferentes. No caso que ele cita, essa guerra está entalhada na fábula mítica do encontro do homem comum com a palavra escrita, como Emma Bovary e Judas Fawley, pouco importando se criada pelo burguês Flaubert ou pelo filho de um mestre-de-obras Hardy.

O que temos que fazer é relacionar a eficácia estética por um lado com a estrutura concreta do campo artístico sendo infiéis a Rancière - e, por outro, com a prática real dos escritores contemporâneos. Devemos recuperar os significados da literatura e as relações entre o campo literário e a sociedade. “Para causar escândalo", afirma Foucault em 1970, "bastava [para Flaubert] restituir em uma obra a realidade cotidiana de uma família burguesa" (FOUCAULT, 2010, p. 247). Isto é, a revolução democrática do sensível operada por escritores do século XIX foi possível devido às condições da época. Foucault acreditava que a literatura nos anos 70 muitas vezes funcionaria como álibi para falar de qualquer coisa, uma reserva da sociedade para 
nomear como não reais experiências reais. Isto é, na literatura - e apenas ali - é permitido falar daquilo que em outras áreas é proibido, o que neutraliza a revolução do sensível.

A transgressão - e nós, da América Latina, do Brasil, talvez estejamos mais aptos a percebê-la do que Rancière está mais em quem pode fazer a literatura e como, misturando registros, gêneros e, mais importante, modos de eficácia discursiva, de maneira indissociável da disputa pelo campo literário. A eficácia estética se perde onde ela não mais coexiste com a eficácia política (seja ela identitária ou territorial). Ela não independe de quem diz e de quem legitima. Dizendo de outra maneira, o qualquer um de Rancière, que ele identifica quase sempre em obras do cânone moderno, é uma hipóstase de um ideal de igualdade inatingível que oblitera as lutas reais do este aqui. Em um sentido, o "qualquer um" é uma figura do trabalho do dissenso. Em outro, pode ser lido como um conceito totalizante demais cuja função é minar o trabalho da crítica em nome de um livre mercado do sensível. A defesa da arte pura (burguesa), afinal, pode ser o recalque da arte política (no Brasil de hoje, periférica).

Não se trata, portanto, de afastar a contribuição de Rancière ou de retomar um esquematismo economicista na relação entre estética e política, mas de reconhecer que - por mais que ela seja útil, talvez mesmo incontornável - precisamos de instrumentos mais adequados aos nossos objetos, latinoamericanos e brasileiros. O que proponho é de certa forma substituir a eficácia estética como uma espécie de concorrência de formas e sujeitos num livre mercado do sensível por uma aliança entre a eficácia estética e a ação política organizada uma ação política que não pretende ditar pedagogicamente o que o outro pode falar, mas mostrar que o semelhante pode falar. Precisamos de constelações teóricas que acatem a impureza dos nossos objetos, ou mesmo a impureza de nosso tempo histórico. Somos ao mesmo tempo mais novos e mais atrasados do que o Ocidente. Ainda estamos caminhando na revolução da alfabetização, que na França começou há 200 anos e permitiu a utopia de Rancière de um público do "homem comum", do qualquer um que pode ser qualquer coisa. Nossa eficácia estética, que rompe sim a partilha policial do sensível, opera de dentro de um regime representativo opressor, e 
acredito que, sem recuperar ideias como as de campos e subcampos e recuperar embates reais e concretos, organizados, não conseguiremos entender a revolução estética que hoje é proposta e convive com um recrudescimento do autoritarismo que sempre esteve presente em nossa sociedade.

\section{REFERÊNCIAS}

DIDI-HUBERMAN, G. O que vemos, o que nos olha. São Paulo: Editora 34, 2013a [1992].

. Diante da imagem. Trad. Paulo Neves. São Paulo, Editora 34, 2013b [1990].

FOUCAULT, M. Ditos e Escritos I. Rio de Janeiro: Editora Forense Universitária, 2010.

FOSTER, H. What's the Problem with Critical Art? London Review of Books, Londres, 10 out. 2013. Disponível em http:// www.lrb.co.uk/v35/n19/hal-foster/whats-the-problem-withcritical-art

MEDEIROS DA SILVA, M. A. A descoberta do insólito: literatura negra e literatura periférica no Brasil (1960-2000). Tese de Doutorado. Campinas, Unicamp, 2011.

MEIHY, J. C. S. B. Repensando Carolina Maria de Jesus. Revista Diversitas, São Paulo, n. 3, p.520-9, abr. 2016. Disponível em https:// www.revistas.usp.br/diversitas/article/view/113905/111761

MICHAELS, W. B. Neoliberal Aesthetics: Fried, Rancière and the Form of the Photograph. nonsite.org, n. 1, 25 jan. 2011. Disponível em: http://nonsite.org/article/neoliberal-aestheticsfried-ranciere-and-the-form-of-the-photograph.

RANCIÈRE, J. A partilha do sensível. São Paulo: Ed. 34/EXO, 2009. . O espectador emancipado. São Paulo: WMF Martins Fontes, 2012. . O ódio à democracia. São Paulo: Boitempo, 2014a [2005]. 
RANCIÈRE, J. El inhallable populismo. In: BADIOU, A. et al. ¿Qué es un pueblo? Buenos Aires: Eterna Cadencia, 2014b, p.119-24.

. Políticas da escrita. São Paulo: Ed. 34, 2017a [1995].

O fio perdido: ensaios sobre a ficção moderna. São Paulo: Martins Fontes, 2017b [2013].

\begin{abstract}
Aesthetic regime and literary field: a reading of Jacques Rancière

In this paper, I discuss the value of the work of Jacques Rancière in the discussion of literature and politics, and the limits of his theory. I review his concepts and recent criticisms of his books, and also use the Brazilian point of view as a privileged prism for an evaluation of his work. I suggest how contemporary literature can be read in the light of concepts such as "distribution of the sensible" and "aesthetic regime", and point out the risks of domesticating this production using a theory that thinks from European and canonical objects.
\end{abstract}

Palavras-chave: Politics; Jacques Rancière; Brazilian literature. 